\title{
Plastic Formulation is an Emerging Control of Its Photochemical Fate in the Ocean
}

\author{
Anna N. Walsh, Christopher M. Reddy, Sydney F. Niles, Amy M. McKenna, Colleen M. Hansel, \\ and Collin P. Ward*
}

Cite This: Environ. Sci. Technol. 2021, 55, 12383-12392

Read Online

\section{ACCESS | Llll Metrics \& More | 回 Article Recommendations | (s) Supporting Information}

ABSTRACT: Sunlight exposure is a control of long-term plastic fate in the environment that converts plastic into oxygenated products spanning the polymer, dissolved, and gas phases. However, our understanding of how plastic formulation influences the amount and composition of these photoproducts remains incomplete. Here, we characterized the initial formulations and resulting dissolved photoproducts of four single-use consumer polyethylene (PE) bags from major retailers and one pure PE film. Consumer PE bags contained 15-36\% inorganic additives, primarily calcium carbonate $(13-34 \%)$ and titanium dioxide $\left(\mathrm{TiO}_{2} ; 1-2 \%\right)$. Sunlight exposure

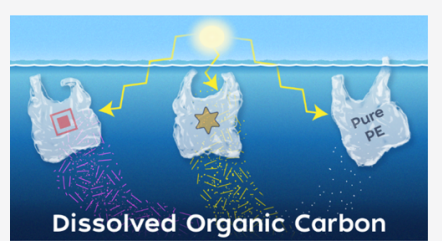
consistently increased production of dissolved organic carbon (DOC) relative to leaching in the dark (3- to 80-fold). All consumer PE bags produced more DOC during sunlight exposure than the pure PE (1.2- to 2.0-fold). The DOC leached after sunlight exposure increasingly reflected the ${ }^{13} \mathrm{C}$ and ${ }^{14} \mathrm{C}$ isotopic composition of the plastic. Ultrahigh resolution Fourier transform ion cyclotron resonance mass spectrometry revealed that sunlight exposure substantially increased the number of DOC formulas detected (1.1- to 50-fold). $\mathrm{TiO}_{2}$-containing bags photochemically degraded into the most compositionally similar DOC, with 68$94 \%$ of photoproduced formulas in common with at least one other $\mathrm{TiO}_{2}$-containing bag. Conversely, only $28 \%$ of photoproduced formulas from the pure PE were detected in photoproduced DOC from the consumer PE. Overall, these findings suggest that plastic formulation, especially $\mathrm{TiO}_{2}$, plays a determining role in the amount and composition of DOC generated by sunlight. Consequently, studies on pure, unweathered polymers may not accurately represent the fates and impacts of the plastics entering the ocean.

KEYWORDS: plastic pollution, marine debris, additives, dissolved organic carbon, photochemical oxidation, FT-ICR-MS, titanium dioxide

\section{INTRODUCTION}

Despite sustained attention from stakeholders, the ultimate fate of marine plastic remains an open question. Historically, stakeholders have assumed that plastics are inert in the environment, with only physical changes occurring. ${ }^{1-5}$ That is, sunlight was once thought to only fragment plastics, producing increasingly small pieces, known as micro- and nanoplastics, that chemically resemble the original material. ${ }^{2,3,6} \mathrm{We}$ now know that sunlight also chemically transforms plastics, releasing a suite of polymer-, dissolved-, and gas-phase products. $^{7-15}$ Despite evidence that photo-oxidation to dissolved organic carbon (DOC) is an important fate of plastics, little is known about the chemical composition of these transformation products.

Orbitrap mass spectrometry (MS) revealed the production of hundreds of water-soluble compounds during ultraviolet (UV) irradiation of several pure polymers. ${ }^{10,14,15}$ However, the achieved mass resolving power of Orbitrap MS is 10-15-fold lower than that of Fourier transform ion cyclotron resonance mass spectrometry (FT-ICR-MS) and its high ion number populations result in peak coalescence, which suggests that we may be underestimating the complexity of plastic photoproducts. $^{16-20}$ Moreover, these initial studies used pure polymers $^{10}$ or polymers containing atypical additives, ${ }^{14,15}$ which may not be representative of the plastics in the environment.

The plastics we use and leak into the environment are widely known to be complex mixtures of polymers and additives, ${ }^{21-23}$ which may influence photochemical behavior. ${ }^{7,24}$ Organic and inorganic additives are common and diverse. Additives are used as fillers (to improve appearance, alter physical properties, and/or reduce cost), pigments, plasticizers, and more. ${ }^{22}$ Little is known about the impacts of plastic formulation on its fate and effects, as studies on marine plastics have generally used pure polymers. However, several recent studies have shown that additive-containing plastics behave differently than pure polymers: photochemical mineralization to $\mathrm{CO}_{2},{ }^{7}$ photooxidation pathways, ${ }^{7,24}$ lability of photoproducts to microbes, ${ }^{25}$ and leachate toxicity ${ }^{26}$ differed between pure and additivecontaining polymers. These early studies suggest that the formulations of plastics in the environment may influence their breakdown by sunlight, but this link remains unconstrained.

Received: May 14, 2021

Revised: August 20, 2021

Accepted: August 23, 2021

Published: September 8, 2021

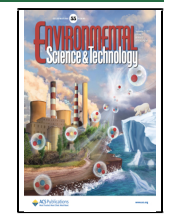


In the present work, we aimed to connect the formulations of single-use consumer polyethylene (PE) bags from major retailers to the amount and composition of DOC produced during sunlight exposure. To achieve this, we first characterized the compositions of four consumer PE bags and one pure PE film. We then irradiated all PE types, measured DOC production, and characterized the composition of the DOC using negative ion electrospray coupled to ultrahigh resolution 21 tesla FT-ICR-MS. We find that plastic formulation substantially influences the amount and chemical composition of DOC generated upon exposure of plastic to sunlight, suggesting that formulation is an emerging control of its fate in sunlit waters.

\section{METHODS}

2.1. Plastic Sources. We chose to conduct these experiments on consumer PE bags because these bags are commonly found in beach surveys ${ }^{27}$ and relevant to regulatory and consumer decision-making. ${ }^{4} \mathrm{PE}$ is also the most widely produced polymer, ${ }^{21}$ the most commonly detected in the ocean, ${ }^{28}$ and buoyant in seawater, ${ }^{1}$ making it susceptible to sunlight exposure. Four consumer PE bags were characterized (Figure S1): conventional disposable shopping bags from Target, CVS, and Walmart and a postconsumer bag from a CVS located in a municipality with a plastic bag ban. An additive-free low-density PE film (Goodfellow) served as a control. Film thickness was measured in duplicate with a NIST-calibrated Mitutoyo micrometer with a precision of 1 $\mu \mathrm{m}$. The Target bags were $26 \pm 2 \mu \mathrm{m}$ [ \pm 1 (standard deviation) SD] thick and white with red writing. The Walmart bags were $19 \pm 2 \mu \mathrm{m}$ thick and gray with blue writing. The postconsumer CVS bags were $79 \pm 6 \mu \mathrm{m}$ thick and off-white with red writing. The conventional CVS bags were $17 \pm 2 \mu \mathrm{m}$ thick and white with red writing. The pure PE was $59 \pm 2 \mu \mathrm{m}$ thick and clear. The text-free areas of the bags were used in experiments. All plastic was cleaned with MilliQ water prior to analysis.

2.2. Characterization of Plastic Optical Properties. UV and visible light absorbance were determined for each bag from transmittance and reflectance measurements on a PerkinElmer Lambda 650s spectrophotometer. Each bag was cut into $\sim 2.5$ $\mathrm{cm} \times \sim 2.5 \mathrm{~cm}$ squares. Transmittance, $T$, was measured using the transmission port and reflectance, $R$, was measured using the reflectance port. Absorbance, $A$, was calculated from the $T$ and $R$ measurements. Absorbance was then converted to Naperian absorption coefficients $\left(a ; \mathrm{m}^{-1}\right)$ by multiplying $A$ by $\ln (10)$ and dividing by the film thickness $(\mathrm{m}) .^{29}$

2.3. Characterization of Additives. Loss on ignition (LOI) measurements were used to determine the organic contents of the bags, with the assumption that leftover ash represents all inorganic additives. The procedure was based on ASTM D 2974-87, the method for determining the ash content of organic matter. ${ }^{29,30}$ Briefly, $\sim 1 \mathrm{~g}$ of each bag $(n=3)$ was placed in a precombusted, preweighed ceramic crucible and combusted at $450{ }^{\circ} \mathrm{C}$ for $8 \mathrm{~h}$. The ash-containing crucible was then reweighed. Samples were also analyzed for the elemental carbon and hydrogen contents (Midwest Microlab), providing an indirect assessment of the presence of organic additives (Appendix 1).

The consumer PE bags and pure PE were sent to the Cambridge Polymer Group for quantification of $\mathrm{Ca}$ and $\mathrm{Ti}$ via inductively coupled plasma mass spectrometry (ICP-MS) using methods similar to those validated and described previously. ${ }^{31}$ All samples were run in duplicate, apart from the Target bag, which was run in triplicate. Samples were digested using microwave heating in a solution containing fluoroboric acid, nitric acid, and phosphoric acid in water. After dilution, samples were analyzed on a PerkinElmer Nexion 350X ICP-MS. The limits of quantification (LOQs) were 5.0 $\mu \mathrm{g} / \mathrm{g}$ for both $\mathrm{Ca}$ and $\mathrm{Ti}$. X-ray diffraction (XRD) was used to identify and quantify the mineral additives within the plastic bags following methods described previously (Appendix 2). ${ }^{32}$

2.4. Quantification of DOC Leached in the Dark and Produced by Sunlight. Leaching of DOC in the dark and during sunlight exposure was measured during two separate experiments. First, DOC was produced for analysis via FTICR-MS. These experiments were conducted in $300 \mathrm{~mL}$ precombusted beakers $\left(450{ }^{\circ} \mathrm{C}\right.$ for $\left.4 \mathrm{~h}\right)$ containing $250 \mathrm{~mL}$ of MilliQ water $(\mathrm{pH} \sim 8)$ covered with quartz lids to avoid contamination from the air. MilliQ water was used instead of seawater to minimize salt suppression during ionization ${ }^{33}$ and avoid masking of the plastic-derived DOC signal by natural seawater DOC (MilliQ DOC concentration was $<2 \mu \mathrm{M}$ for these experiments). The results of several experiments demonstrate that the photochemical behavior of plastics in MilliQ water is representative of behavior in natural waters (Appendix 3). To ensure sufficient DOC production, plastic was cut into $\sim 3 \mathrm{~cm} \times \sim 1 \mathrm{~cm}$ pieces and $\sim 0.5-4.2 \mathrm{~g}$ was used for the dark controls and $\sim 0.5 \mathrm{~g}$ was used for the light-exposed samples. The light-exposed Target, conventional CVS, and postconsumer CVS bags were run in duplicate, while a single sample was run for all others. Dark controls were covered in foil, then placed in a dark drawer for 6 days at room temperature. Light-exposed beakers were placed inside an Atlas XLS+ solar simulator equipped with a long-arc Xe lamp and Daylight filter (Ametek Inc.) in a custom anodized water bath connected to a chiller, which maintained the beakers at $25 \pm 5$ ${ }^{\circ} \mathrm{C}$ during the experiment. A NIST-calibrated spectral radiometer (StellarNet, Inc.) was used to quantify irradiance. Relative to natural sunlight at 0 and $50^{\circ} \mathrm{N}$, simulated sunlight was 4- and 12-fold greater, respectively (Figure S2 and Table S2). After 5 days of irradiation or 6 days in the dark, the mass of the water was measured and samples were filtered through a GF/F filter. MilliQ was added to account for evaporation in the light-exposed samples. Samples were then acidified to $\mathrm{pH}$ $\sim 2$ with trace metal grade $6 \mathrm{~N}$ hydrochloric acid $(\mathrm{HCl})$ and analyzed for DOC concentration on a Shimadzu 5000A TOC analyzer.

The remaining DOC was extracted from samples using Agilent Bond Elut PPL cartridges, following Dittmar et al. ${ }^{34}$ After cleaning the cartridge with $2 \mathrm{~mL}$ methanol, samples were loaded onto the cartridge at a flow rate of $\sim 30 \mathrm{~mL} / \mathrm{min}$. After loading the samples onto the cartridges, $2 \mathrm{~mL}$ of $0.01 \mathrm{M} \mathrm{HCl}$ was passed through the cartridge. Immediately after, samples were dried under vacuum for $5 \mathrm{~min}$. Finally, samples were eluted with $1 \mathrm{~mL}$ methanol directly into combusted $2 \mathrm{~mL}$ vials. While DOC recoveries were not determined, previous studies have reported incomplete recoveries on the order of $60 \%$ for seawater DOC ${ }^{34}$ and terrestrial DOC. ${ }^{35}$ Incomplete recoveries via PPL extraction indicate that DOC complexity was underestimated. We do not anticipate substantial differences in recoveries between samples because all plastic-derived DOC shared similar, wide-ranging elemental compositions. Extracts were shipped on ice overnight for FT-ICR-MS analysis.

Separately, a time series experiment was conducted using the postconsumer CVS bag. For both the light-exposed and dark 

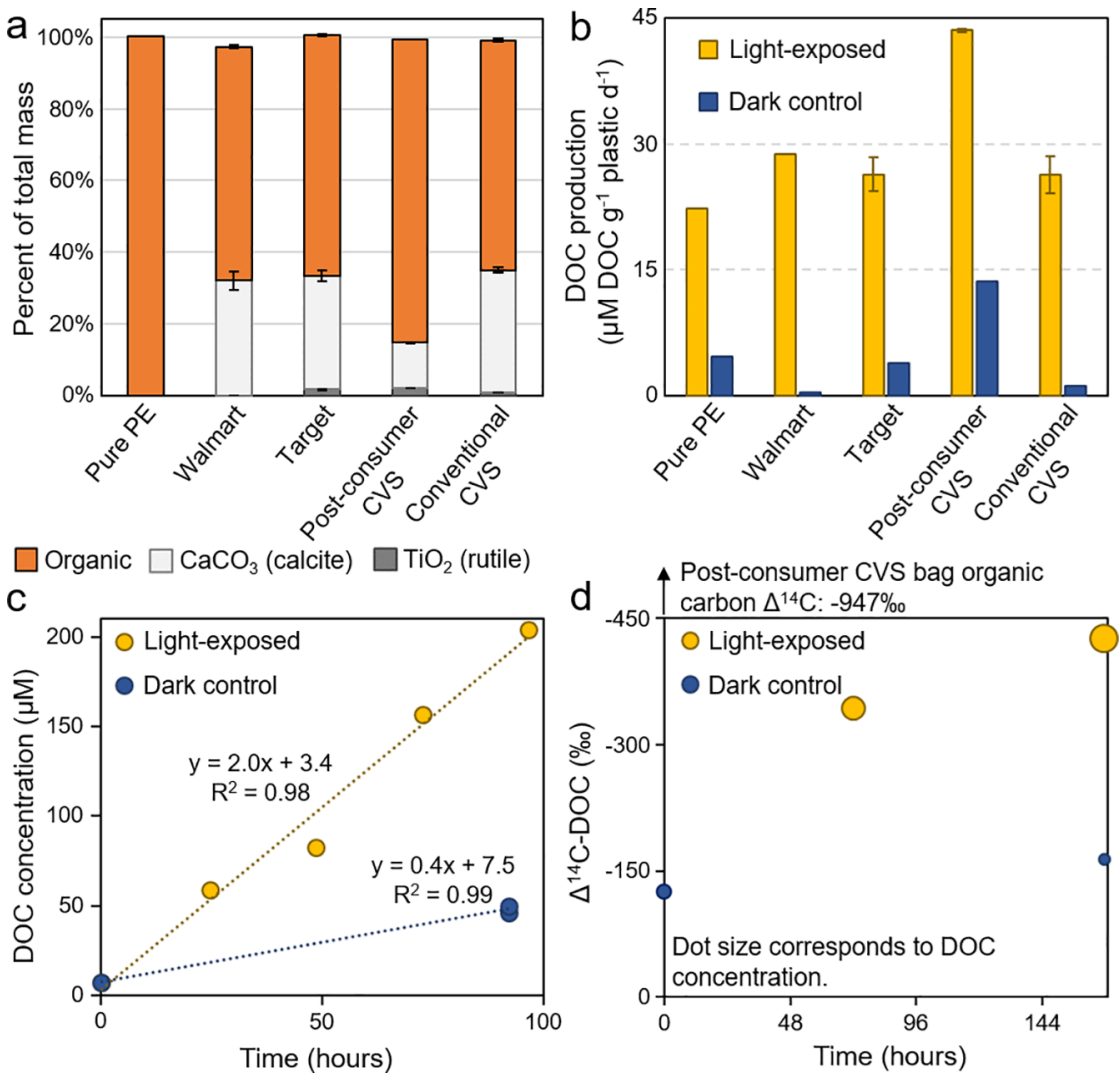

Figure 1. (a) Composition breakdowns for each sample, with organic percent from $\mathrm{LOI}$ and $\mathrm{CaCO}_{3}$ and $\mathrm{TiO}_{2}$ percent from ICP-MS. Mineral form was determined via XRD. Error bars represent \pm 1 SD $(n=2-3)$. (b) DOC produced by pure PE and consumer PE bags during exposure to simulated sunlight and in the dark normalized by the mass of plastic and exposure time. Error bars represent \pm 1 SD $(n=1-2)(\mathrm{c})$ DOC produced by the postconsumer CVS bag during 1, 2, 3, and 4 days of exposure to simulated sunlight, alongside dark controls at 0 and 4 days. (d) $\Delta^{14} \mathrm{C}$ of DOC produced by the postconsumer CVS bag during exposure to simulated sunlight and in the dark. Dot size corresponds to the DOC concentration (Table S5).

control samples, $\sim 5 \mathrm{~g}$ of plastic cut into $\sim 1 \times \sim 8 \mathrm{~cm}$ strips were placed floating on top of $\sim 2.3 \mathrm{~L}$ MilliQ water in a combusted Pyrex dish $(34 \times 23 \mathrm{~cm})$. The dish was placed inside the solar simulator in a water bath, which maintained the plastic at $30 \pm 5{ }^{\circ} \mathrm{C}$ during the experiment, and covered with UV-B and UV-A transmitting acrylic (Arkema Inc.), which served as a thermal barrier by absorbing infrared light. In this configuration, simulated sunlight was 3 - and 12-fold greater than natural sunlight at 0 and $50^{\circ} \mathrm{N}$, respectively (Figure S3 and Table S3). An initial $\sim 35 \mathrm{~mL}$ sample was taken immediately after placing the plastic in the water. After 1, 2, 3 , and 6 days of irradiation, $\sim 35 \mathrm{~mL}$ water samples were taken from the dish and an equivalent amount of MilliQ water was replaced in the dish. Simultaneously, a dark control covered in foil was kept in the dark and $\sim 35 \mathrm{~mL}$ samples were taken in duplicate after 6 days. All samples were then analyzed for DOC concentration.

2.5. Isotopic Characterization of DOC Leached in the Dark and Produced by Sunlight. Natural abundance radiocarbon measurements were leveraged to track the conversion of the postconsumer CVS bag to DOC. The same configuration from the time series experiment was used, with some modifications. The experiments were conducted in Vineyard Sound seawater filtered with GF/F and Sterivex filters to ensure that all samples had a sufficiently high background DOC concentration to obtain a robust determination of the radiocarbon content. ${ }^{36}$ Seawater also contains DOC that is more modern than the fossil OC in the PE, increasing the potential to see large shifts in DOC $\Delta^{14} \mathrm{C}$ as the PE-derived DOC is added to the pool during irradiation. Separate exposures were run for 3 and 7 days and separate dark controls were included for 0 (i.e., water was sampled immediately after placing the plastic in it) and 7 days. All samples were filtered into a combusted $500 \mathrm{~mL}$ bottle using a GF/F filter and submitted to the National Ocean Sciences Accelerator Mass Spectrometry facility for $\delta^{13} \mathrm{C}$ and $\Delta^{14} \mathrm{C}$ measurements. Initial carbon isotope measurements of the bulk, organic, and inorganic fractions of the postconsumer CVS bag were taken in duplicate using a novel two-step method described in Appendix 4.

2.6. Characterization of DOC Leached in the Dark and Produced by Sunlight Using FT-ICR-MS. DOC composition was characterized using the 21 tesla (T) FTICR-MS at Florida State University's National High Magnetic Field Laboratory using methods described in Appendix 5. 19,20 In short, water-soluble extracts were infused directly into the mass spectrometer at $0.5 \mu \mathrm{L} / \mathrm{min}$ for negative-ion (-) electrospray ionization (ESI) analysis. The light-exposed Target, conventional CVS, and postconsumer CVS bags were run in duplicate, while a single sample was run for the lightexposed Walmart bag and pure PE and all dark controls. Predator analysis ${ }^{37}$ and PetroOrg ${ }^{38}$ software were used for internal "walking" calibration ${ }^{39}$ of absorption mode spectra ${ }^{40}$ and subsequent elemental composition assignments. 


\section{RESULTS}

\subsection{Characterization of Plastic Optical Properties.} The UV and visible light absorption spectrum of the pure PE was distinct from that of the consumer-grade PE (Figure S4). The pure PE showed minimal light absorption throughout the $\mathrm{UV}$ and visible regions, as expected for pure PE. ${ }^{41}$ In contrast, all bags had absorption spectra distinct from the pure PE, suggesting the presence of additives. The Target, conventional CVS, and postconsumer CVS bags showed similar, strong absorption across the UV, followed by a sharp decline in absorption at $\sim 400 \mathrm{~nm}$. This spectral shape is characteristic of $\mathrm{TiO}_{2}{ }^{42}$ The Walmart bag instead showed strong absorption across the UV and visible regions, characteristic of the absorption properties of carbon black. ${ }^{43}$

3.2. Characterization of Additives. LOI measurements demonstrated that the pure PE was indeed free of inorganic additives, while the consumer PE bags were not. $100 \pm 0.1 \%$ $( \pm 1 \mathrm{SD}, n=3)$ of the pure PE was lost on ignition (Figure la and Table S4), indicating that only organic material was present. In contrast, LOI was consistently below $100 \%$ for all consumer PE bags. The postconsumer CVS bag had the highest LOI value among the bags, with $85 \pm<0.1 \%$, followed by the Target bag with $67 \pm 0.3 \%$, the Walmart bag with $65 \pm$ $0.5 \%$, and the conventional CVS bag with $64 \pm 0.1 \%$. This result indicated that approximately $15,33,35$, and $36 \%$ of the masses of the postconsumer CVS, Target, Walmart, and conventional CVS bags, respectively, were inorganic additives. Elemental analysis suggests that the organic fractions of all materials were predominantly PE (Appendix 1 and Table S1).

The absence and presence of inorganic additives in the pure $\mathrm{PE}$ and consumer PE bags, respectively, were confirmed by ICP-MS. In the pure PE, Ca and Ti were below or near their respective LOQs (Table S4). In contrast, $\mathrm{Ca}$ and $\mathrm{Ti}$ in all consumer PE bags were orders of magnitude above the LOQs. The conventional CVS bag had the highest Ca concentration $(136 \pm 3.1 \mathrm{mg} / \mathrm{g} ; \pm 1 \mathrm{SD}, n=2)$, followed by the Walmart and Target bags ( $130 \pm 10$ and $130 \pm 6.3 \mathrm{mg} / \mathrm{g}$, respectively), and the postconsumer CVS bag $(51 \pm 0.9 \mathrm{mg} / \mathrm{g})$. Relative to $\mathrm{Ca}$, much lower concentrations of $\mathrm{Ti}$ were observed in the consumer PE bags. The postconsumer CVS bag had the highest concentration of $\mathrm{Ti}(13 \pm<0.005 \mathrm{mg} / \mathrm{g})$, followed by the Target bag $(11 \pm 0.6 \mathrm{mg} / \mathrm{g})$, the conventional CVS bag $(6.5 \pm 0.07 \mathrm{mg} / \mathrm{g})$, and the Walmart bag $(0.7 \pm 0.01 \mathrm{mg} / \mathrm{g})$. By assuming that $\mathrm{Ca}$ and $\mathrm{Ti}$ are primarily added to plastics as $\mathrm{CaCO}_{3}$ and $\mathrm{TiO}_{2}$, we calculated that the Walmart bag contained $32 \pm 2.6 \% \mathrm{CaCO}_{3}$ and $0.1 \pm 0.001 \% \mathrm{TiO}_{2}$, the Target bag contained $32 \pm 1.6 \% \mathrm{CaCO}_{3}$ and $1.8 \pm 0.1 \% \mathrm{TiO}_{2}$, the postconsumer CVS bag contained $13 \pm 0.2 \% \mathrm{CaCO}_{3}$ and $2.2 \pm<0.001 \% \mathrm{TiO}_{2}$, and the conventional CVS bag contained $34 \pm 0.8 \% \mathrm{CaCO}_{3}$ and $1.1 \pm 0.01 \% \mathrm{TiO}_{2}$.

XRD confirmed our assumption that $\mathrm{CaCO}_{3}$ and $\mathrm{TiO}_{2}$ were the major inorganic additives in the $\mathrm{PE}$ bags (Figures 1a, S5 and Table S6). Neither $\mathrm{CaCO}_{3}$ nor $\mathrm{TiO}_{2}$ was detected in the pure PE. In contrast, the Target, conventional CVS, and postconsumer CVS bags contained calcite and rutile, which were the only detectable crystalline components in each bag. The proportions of $\mathrm{CaCO}_{3}$ and $\mathrm{TiO}_{2}$ relative to the total mass of inorganic additives were $86.7 \pm 1.9$ and $13.2 \pm 1.1 \%$, respectively, in the postconsumer CVS bag, $95.0 \pm 1.9$ and 5.1 $\pm 1.2 \%$, respectively, in the Target bag, and $97.6 \pm 1.0$ and 3.4 $\pm 0.9 \%$, respectively, in the conventional CVS bag $( \pm 1 \mathrm{SD}, n=$
3). The only detectable crystalline structure in the Walmart bag was calcite.

Combining the LOI, ICP-MS, and XRD results achieved $100 \%$ mass balances of the compositions of each PE sample (Figure 1a). Moreover, excellent agreement was observed between the LOI, ICP-MS, and XRD data. Plotting the sum of $\mathrm{CaCO}_{3}$ and $\mathrm{TiO}_{2}$ calculated from the ICP-MS data against the ash content from LOI yields a nearly $1: 1$ line $\left(R^{2}=0.97\right)$ (Figure S6). Similarly, plotting the percent of $\mathrm{CaCO}_{3}$ (relative to $\mathrm{TiO}_{2}$ ) measured via ICP-MS against the percent measured via XRD also yields a nearly $1: 1$ line $\left(R^{2}=0.99\right)$ (Figure S7).

3.3. Quantification of DOC Leached in the Dark and Produced by Sunlight. For the pure PE and the consumer PE bags, a small amount of DOC leached in the dark, but a much greater amount leached in the presence of sunlight (Figure 1b). In the dark controls, the smallest amount of DOC leached out of the Walmart bag $\left(0.35 \mu \mathrm{M}\right.$ DOC g ${ }^{-1}$ plastic

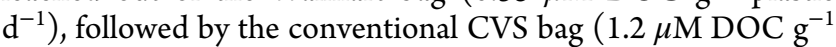

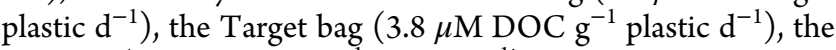
pure PE $\left(4.6 \mu \mathrm{M} \mathrm{DOC}^{-1}\right.$ plastic $\left.\mathrm{d}^{-1}\right)$, and the postconsumer CVS bag $\left(14 \mu \mathrm{M}\right.$ DOC $\mathrm{g}^{-1}$ plastic $\left.\mathrm{d}^{-1}\right)$. Following light exposure, DOC concentration increased for all samples. The pure PE had the lowest difference between light-exposed and

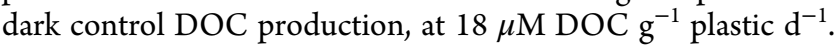
Among the consumer PE bags, the postconsumer CVS bag had the greatest difference between light-exposed and dark control DOC production, followed by the Walmart, conventional CVS, and Target bags, at $30 \pm 0.2 \mu \mathrm{M} \mathrm{DOC} \mathrm{g}^{-1}$ plastic $\mathrm{d}^{-1}( \pm 1 \mathrm{SD}$, $n=2), 28 \mu \mathrm{M} \mathrm{DOC} \mathrm{g}^{-1}$ plastic $\mathrm{d}^{-1}(n=1), 25 \pm 2.2 \mu \mathrm{M}$ DOC $\mathrm{g}^{-1}$ plastic $\mathrm{d}^{-1}(n=1)$, and $23 \pm 2.0 \mu \mathrm{M}$ DOC g $\mathrm{g}^{-1}$ plastic $\mathrm{d}^{-1}$ $(n=2)$, respectively. This represents 3.2-, 4.8-, 6.9-, 23-, and 83 -fold increases from dark to light DOC production for the postconsumer CVS bag, pure PE, Target bag, conventional CVS bag, and Walmart bag, respectively.

Increasing durations of sunlight exposure led to an increasing amount of DOC leaching from the postconsumer CVS bag (Figure 1c). After $97 \mathrm{~h}$ of irradiation with simulated sunlight, $154 \mu \mathrm{M}$ DOC were produced. The increase over four time points was linear $\left(R^{2}=0.98\right)$. In contrast, the dark control DOC concentration increased to only $48 \pm 2.7 \mu \mathrm{M}(n=2)$ after $92 \mathrm{~h}$.

3.4. Isotopic Characterization of DOC Leached in the Dark and Produced by Sunlight. Initial measurements of the postconsumer CVS bag's isotopic signature confirmed that the organic carbon was primarily fossil $\left(\delta^{13} \mathrm{C}=-29.4 \%\right.$; $\Delta^{14} \mathrm{C}$ $=-947 \%$; Table S5), consistent with petroleum feedstocks. The small amount of modern carbon was likely due to modern additives or impurities from the manufacturing process. The inorganic carbon also showed a fossil radiocarbon signature, but $\delta^{13} \mathrm{C}$ was substantially more enriched $\left(\delta^{13} \mathrm{C}=-6.3 \%\right.$ and $\Delta{ }^{14} \mathrm{C}=-970 \%$ ), consistent with the limestone typically used for calcium carbonate fillers.

Natural abundance radiocarbon measurements confirmed that the postconsumer CVS bag was converted to DOC (Figure $1 \mathrm{~d}$ and Table S5). The 0 day dark control was consistent with coastal seawater $\left[(\mathrm{DOC})=101 \mu \mathrm{M} ; \delta^{13} \mathrm{C}\right.$ lost during measurement; $\Delta^{14} \mathrm{C}=-126 \%$ ]. The 7 day dark control showed a small decrease in $\Delta^{14} \mathrm{C}$, consistent with leaching of fossil DOC from the plastic ([DOC] $=83 \mu \mathrm{M}$; $\delta^{13} \mathrm{C}=-23.8 ; \Delta^{14} \mathrm{C}=-163 \%$ ). The slight decrease in DOC in the dark is likely due to experimental differences in $\mathrm{C}$ recovery. ${ }^{36}$ Light-exposed samples showed appreciable increases in DOC concentration and decreases in DOC $\delta^{13} \mathrm{C}$ and 
$\Delta{ }^{14} \mathrm{C}$ corresponding to DOC production from the plastic. After 3 days of irradiation, the DOC concentration increased by $78 \mu \mathrm{M}$, relative to the average of the dark controls, and $\delta^{13} \mathrm{C}$ and $\Delta^{14} \mathrm{C}$ decreased to -26.6 and $-343 \%$, respectively. After 7 days of irradiation, the DOC concentration increased by 100 $\mu \mathrm{M}$, relative to the average of the dark controls, and $\delta^{13} \mathrm{C}$ and $\Delta^{14} \mathrm{C}$ decreased to -27.1 and $-424 \%$, respectively. Isotopic mass balance calculations revealed that photo-produced DOC had a more modern signature than expected, based on the measured organic carbon isotope signature of the initial plastic (Appendix 4). After 3 and 7 days of light exposure, the calculated $\Delta^{14} \mathrm{C}$ of the DOC added from the plastic was -585 and $-689 \%$, respectively, whereas the measured $\Delta^{14} \mathrm{C}$ of the organic carbon fraction of the plastic was $-947 \%$. This result suggests that the modern carbon additives were preferentially oxidized to DOC, but, with time, the proportion of fossil, polymer-derived DOC increases. Alternative and less likely interpretations of the results include the preferential mineralization of aged DOC in the marine DOC pool and enhanced leaching of oxygenated, water-soluble organic additives after sunlight exposure (Appendices 1, 4 and Table S1).

3.5. Characterization of DOC Leached in the Dark and Produced by Sunlight Using FT-ICR-MS. The number of assigned formulas in DOC that leached in the dark ranged widely depending on the type of PE (Figures 2, S8 and Table

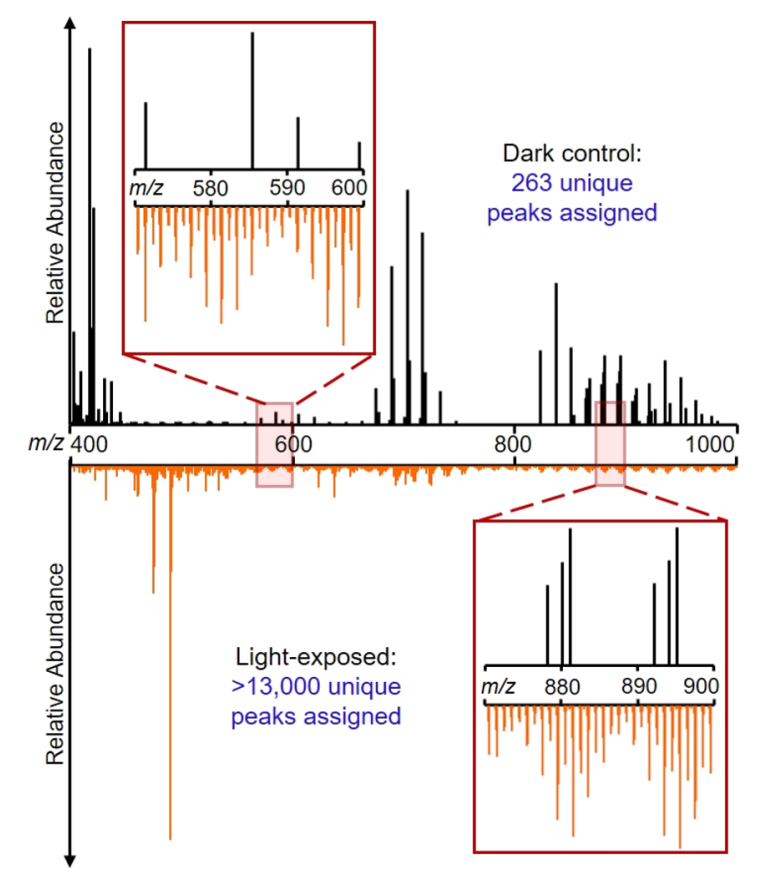

Figure 2. Negative ion ESI $21 \mathrm{~T}$ FT-ICR mass spectra of peaks unique to dark control (black) and photoproduced DOC (orange) for the conventional CVS bag. This bag is generally representative of the trends observed for all samples (Figure S8).

S7). The pure PE had 1464 formulas unique to the dark control. A range spanning 2 orders of magnitude was observed for the consumer PE bags: the conventional CVS bag contained the fewest formulas unique to the dark control (263), followed by the Target (476), Walmart (1387), and postconsumer CVS $(11,027)$ bags.

By most metrics, average DOC chemical composition leached in the dark from the pure PE and the bags was similar
(Figure 3 and Table S7). The average molecular weight for the pure PE was similar to the consumer PE bags, at 537, compared to $445,486,626$, and 642 for the Target, conventional CVS, postconsumer CVS, and Walmart bags, respectively. The average carbon number for the pure $\mathrm{PE}$ was 30 , while the average was 23 for the Target bag, 28 for the conventional CVS bag, 33 for the postconsumer CVS bag, and 38 for the Walmart bag. The average number of oxygen atoms was eight in the pure PE, compared to six in the conventional CVS and Walmart bags, seven in the Target bag, and 11 in the postconsumer CVS bag. Average $\mathrm{H} / \mathrm{C}$ ratios overlapped, with 1.5 in the pure PE, Target, and conventional CVS bags, 1.4 in the postconsumer CVS bag, and 1.3 in the Walmart bag. O/C ratios were also similar, with the pure $\mathrm{PE}$ and Target bag at 0.3 , the postconsumer CVS bag at 0.4, and the Walmart and conventional CVS bags at 0.2 . All replicates showed consistent trends.

Sunlight exposure substantially increased the number of DOC formulas leached from all PE samples (Figures 2, S8 and Table S7). The pure PE had among the fewest formulas in the light-exposed sample (9030). Of the bags, the Walmart bag had the most formulas $(15,353)$, followed by the conventional CVS (13,052), postconsumer CVS $(12,312)$, and Target bags (5359). The pure PE increased by 6-fold from dark to light. Among the consumer PE bags, the largest increase was observed for the conventional CVS bag (50-fold), followed by the Target and Walmart bags (11-fold), and the postconsumer CVS bag (1.1-fold).

The composition of the DOC leached in the dark and produced by sunlight showed many similarities, but average carbon numbers and molecular weights were noteworthy exceptions (Figures 3, S8 and Table S7). These differences were generally larger for consumer PE bags, especially those containing $\mathrm{TiO}_{2}$. Average carbon numbers were consistently greater in the photoproduced DOC than in the DOC leached in the dark, with the lowest observed for the pure PE, at 30, followed by 32 for the Target bag, 38 for the conventional CVS bag, 39 for the postconsumer CVS bag, and 40 for the Walmart bag. A similar trend was observed for average molecular weight: the pure $\mathrm{PE}$ was among the lowest, at 608 , compared to $583,663,688$, and 698 for the Target, conventional CVS, Walmart, and postconsumer CVS bags, respectively. Average numbers of oxygen atoms increased for most samples, while $\mathrm{H} / \mathrm{C}$ ratios and $\mathrm{O} / \mathrm{C}$ ratios remained similar for dark control and light-exposed samples.

Sunlight exposure converted the pure PE into DOC that was compositionally distinct from the DOC produced from the consumer PE bags (Figures 3, S8, S9 and Table S8). The pure $\mathrm{PE}$ contained the highest percent of unique formulas (72\%) relative to the photoproduced DOC from the other samples $(6-41 \%)$. The formulas unique to the bags were more tightly clustered in van Krevelen space, with $\mathrm{H} / \mathrm{C}$ ratios ranging from $\sim 1-2$ and $\mathrm{O} / \mathrm{C}$ ratios from $\sim 0.2-0.5$. In contrast, the pure $\mathrm{PE}$ showed a greater spread, with $\mathrm{H} / \mathrm{C}$ ratios ranging from $\sim 0.7-$ 1.9 and $\mathrm{O} / \mathrm{C}$ ratios from $\sim 0.1-0.9$. Photoproduced DOC unique to the pure PE was more oxidized and lower molecular weight compared to photoproduced DOC unique to the consumer bags.

Consumer PE bag composition further influenced photoproduced DOC composition. The greatest similarities were observed between the three $\mathrm{TiO}_{2}$-containing bags, for which $68-94 \%$ of photoproduced formulas in each $\mathrm{TiO}_{2}$-containing bag were shared with those generated by at least one other 


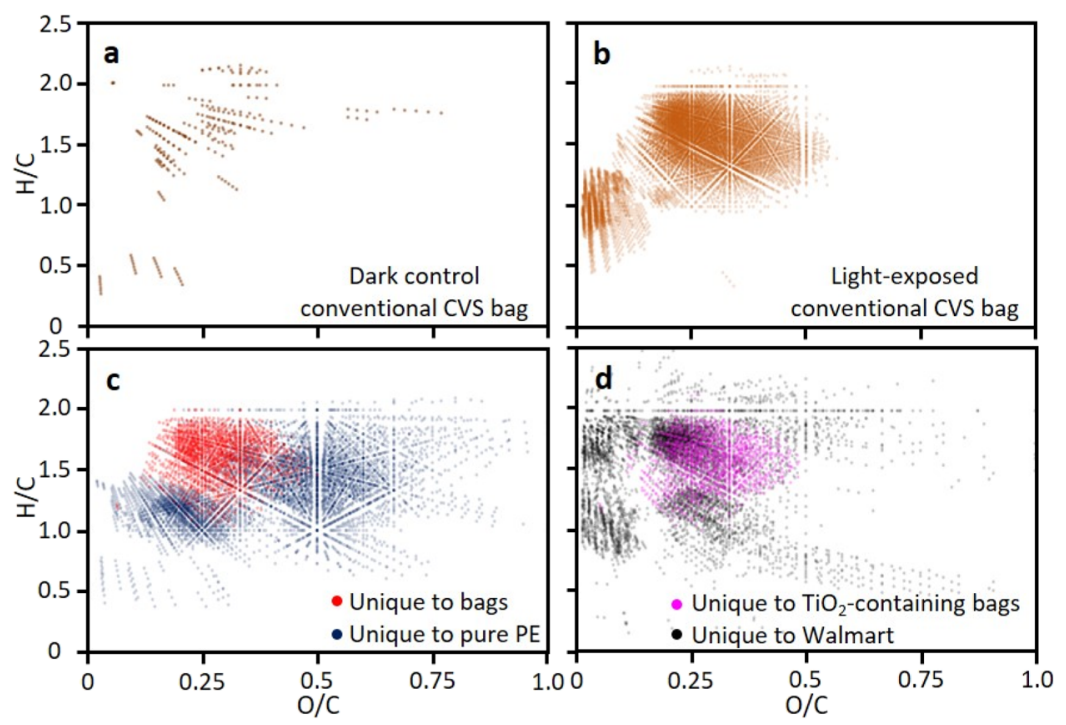

Figure 3. van Krevelen diagrams showing (a) formulas unique to the conventional CVS bag dark control relative to the light-exposed sample, (b) formulas unique to the light-exposed conventional CVS bag relative to the dark control, (c) a comparison between formulas found only in photoproduced DOC from consumer PE bags (Walmart, Target, and conventional and postconsumer CVS bags), shown in red, and formulas found only in photoproduced DOC from the pure PE, shown in blue, and (d) a comparison between the formulas found only in photoproduced DOC from the $\mathrm{TiO}_{2}$-containing bags (Target and conventional and postconsumer CVS bags) (pink) and formulas found only in photoproduced DOC from the Walmart bag (black).

$\mathrm{TiO}_{2}$-containing bag (Figure 3 and Table S8). The Walmart bag shared $43 \%$ of formulas with at least one other consumer PE bag. In contrast, only $28 \%$ of the photoproduced formulas from the pure PE were detected in any of the consumer bags. Put another way, the $\mathrm{TiO}_{2}$-containing bags had nearly 4000 formulas in common between all three, substantially more than the Walmart bag $(\sim 2600)$. The pure PE shared only $\sim 700$ formulas with all bags. Formulas unique to the $\mathrm{TiO}_{2}$ containing bags clustered more tightly across van Krevelen space, with $\mathrm{H} / \mathrm{C}$ ratios ranging from $\sim 1.2-1.9$ and $\mathrm{O} / \mathrm{C}$ ratios ranging from $\sim 0.2-0.5$. In contrast, the formulas unique to the Walmart bag spread widely across van Krevelen space, with $\mathrm{H} /$ $\mathrm{C}$ ratios ranging from $\sim 0.4-2.4$ and $\mathrm{O} / \mathrm{C}$ ratios ranging from $\sim 0-0.8$. Consistent with the compositional differences observed in the van Krevelen diagrams, the percent (by mass) of inorganic additives was significantly inversely correlated with the average number of oxygen atoms in the formulas unique to the light-exposed samples $\left(R^{2}=0.96 ; p=\right.$ 0.004).

\section{DISCUSSION}

4.1. Impact of Photodegradation on Plastic Fate. These findings add to the growing body of literature suggesting that photochemical oxidation of plastic to DOC is an important fate of marine plastic. While even the pure $\mathrm{PE}$ leaches some DOC in the dark-likely processing impurities, by-products, and oligomers ${ }^{22}$-light exposure consistently produces substantially more DOC (Figure $1 \mathrm{~b}$ ). Moreover, photoproduction of DOC increases linearly with sunlight exposure time (Figure 1c), and radiocarbon measurements demonstrate that the added DOC is plastic-derived (Figure 1d). Although we focused on PE-based plastics, several studies on DOC photoproduction from other polymers (e.g., polystyrene, polypropylene, and PE terephthalate) suggest that our results are relevant to a broader class of plastic materials. $^{7-11,13-15,24,44}$ This is because all polymers are susceptible to chain scission and oxidation reactions, ${ }^{11}$ the inorganic additives detected in this study are commonly used in formulations with other polymers, ${ }^{22}$ and several other studies using Orbitrap MS reported that multiple polymer types are susceptible to photodissolution. ${ }^{10,14,15}$ Thus, the present work and previous research on this topic collectively suggest that photochemical DOC production is an important fate of plastics in the environment.

Exposure of PE standards and consumer products to sunlight generates tens of thousands of water-soluble compounds (i.e., DOC) on timescales of weeks. These photoproducts span wide ranges in composition (i.e., $\mathrm{H} / \mathrm{C}$, $\mathrm{O} / \mathrm{C}$, molecular weight; Figures 3, S8, S9 and Table S7) and depend on the composition of the plastic being degraded (Figures 1a and 3). While prior work has reported the generation of hundreds of photochemical transformation products from $\mathrm{PE}$ degradation over timescales of years, ${ }^{10}$ here we reveal that under more environmentally relevant timescales and conditions, this process yields a mixture of photoproducts that is approximately an order-of-magnitude more complex than previously understood. This revelation was likely made possible for two reasons. First, by screening powerful UVC radiation that does not reach Earth's surface and conducting shorter-term incubations (equivalency of weeks vs years), our experimental design likely maximized the buildup of photochemical intermediates that were subsequently characterized using FT-ICR-MS. Second, the 21 T FT-ICR-MS far outweighs the Orbitrap mass spectrometer in resolving power (10-15-fold higher) and mass accuracy (20-fold higher). ${ }^{19,20}$ In this study, the mass resolving power using $21 \mathrm{~T}$ FT-ICR-MS was $1,300,000$ at $\mathrm{m} / \mathrm{z}$ 400 , enabling us to resolve compounds that may otherwise be overlooked. This experimental design provides the community with a viable path forward toward comprehensively characterizing the diverse array of consumer plastic photoproducts released into aquatic ecosystems.

The growing evidence ${ }^{7-15}$ that photochemical transformation of plastics is an important transformation process in 
surface waters challenges a widely held assumption about the persistence of plastic in the environment. Numerous stakeholders of this environmental issue, including the scientific community, policymakers, industry, media, and the public, assume that sunlight exposure merely physically fragments macroplastics to microplastics, which subsequently persist forever in the environment. ${ }^{1-5}$ For example, a recently published set of guidelines for monitoring and assessing plastic litter in the ocean states that: "plastic fragments will have similar structural properties as larger items of the same polymer". 1 Our findings, along with those from the literature, ${ }^{7,9,10,14,15,45-47}$ fundamentally challenge this guideline and indicate that sunlight not only aids physical fragmentation of plastic, it chemically alters it, producing a suite of transformation products that no longer resemble the parent material. Therefore, we suggest that these guidelines be updated to accurately reflect the fate of plastic in the sunlit environment.

Many organic compounds once hypothesized to be inert in the environment are now understood to be labile to degradation. Over the past several decades, many supposedly indestructible materials, including lignin, ${ }^{35,48-51}$ black carbon, ${ }^{29,52,53}$ and asphaltenes, ${ }^{54}$ have eventually been found to have an Achilles heel: sunlight. Like plastics, each of these materials is now known to photodegrade into thousands of unique products. ${ }^{29,35,54}$ While it is becoming increasingly clear that plastics are not inert in the environment, more work to determine degradation rates (including variations over space and time), ${ }^{7}$ effects of environmental factors (e.g., biofouling, ${ }^{55}$ wavelength-dependence, ${ }^{7}$ residence time in the photic zone, etc.), and transformation products is needed to fully understand the fate of plastics in the environment.

4.2. Influence of Additives on Plastic Photodegradation. Our findings suggest that consumer plastic formulations vary widely, leading to differences in the amount of plastic converted to DOC by sunlight. Inorganic additives comprise a substantial portion of all consumer PE bags tested, with around one-third of total plastic mass comprised by additives (Figure 1a). This is not unique to single-use plastic bags; consumer plastics are well known to contain a variety of additives, ${ }^{22,23}$ with additives accounting for $\sim 7 \%$ of plastic production in $2015 .^{21}$ It appears that as a result of these composition differences, all consumer PE bags produced more DOC than the pure PE (Figure 1b). Consistent with our observations, previous studies have shown that consumer-relevant formulations degrade faster than their pure analogues. ${ }^{7,24}$ Therefore, to determine environmentally relevant photodegradation kinetics and lifetimes of marine plastics, it is critical to study consumerrelevant formulations.

In addition to driving the amount of DOC produced during sunlight exposure, additives also drive the chemical composition of the DOC. While each bag produced unique DOC formulas, the consumer PE bags had more in common with one another than the pure PE (Figures 3, S9 and Table S8). The presence of $\mathrm{TiO}_{2}$, a common white pigment, especially appeared to drive large similarities between bags containing this additive, which had $68-94 \%$ of formulas in common. This likely reflects the different mechanism for $\mathrm{TiO}_{2}$-catalyzed degradation, which is largely driven by hydroxyl radicals. ${ }^{42,56} \mathrm{In}$ contrast, photodegradation of pure $\mathrm{PE}$ is driven by chain scission reactions, with dissolved oxygen as the primary oxidant. ${ }^{10,11}$ The strong inverse relationship between inorganic additives and the average number of oxygen atoms in the formulas unique to light-exposed samples also suggests that other factors related to the inorganic additives are at play. While the precise mechanism driving this relationship is not clear, particulate inorganic additives are known to alter the plastic's physical properties (e.g., surface area and light scattering) and require coatings and other processing aids to facilitate dispersion within the polymer matrix. ${ }^{57-60}$ Many other additives beyond the ones we identified in the bags, including organic ones, have the potential to alter the photodegradation mechanism and, as a result, DOC quantity and quality. ${ }^{22,24}$ Future studies conducted under more controlled conditions should constrain the effects of specific additives, inorganic and organic, on photoproduced DOC quantity and quality, including potential synergy and antagonism between additives.

4.3. Implications for Plastics in the Environment. Our results indicate that pure, unweathered plastics are poor proxies for studying the fate and impacts (e.g., toxicity, ${ }^{61-63}$ biogeochemical processes, ${ }^{25,64-66}$ and biofouling ${ }^{55}$ ) of plastics in the environment. We have known for decades that the plastics in the environment are complex mixtures that undergo weathering processes and release micro- and nanoplastics. ${ }^{67}$ Here, we demonstrate that plastics are susceptible to photodegradation on timescales relevant to transit times in surface waters (i.e., weeks to months), yielding tens of thousands of unregulated compounds with unconstrained fates and impacts (Figures 2, 3, S8, S9 and Table S7). Moreover, plastic formulation, which varies widely even for the exact same consumer article (Figure 1a), substantially influences the amount and chemical composition of DOC leached from plastic upon exposure to sunlight (Figures $1 \mathrm{~b}$ and 3 ). Yet, the plastic sciences discipline continues to rely on pure, unweathered materials in their experimental frameworks.

Using the plastic toxicity literature as an example, we surveyed 78 plastic toxicity studies referenced in three relatively recent and well-cited reviews ${ }^{61-63}$ to determine the proportion of studies that considered plastic formulation and environmental weathering. Among the 78 studies we surveyed, only $33 \%$ included consumer goods. Of the $13 \%$ that compared consumer goods with their pure analogues, all observed differences in toxicity. Only $15 \%$ of the 78 toxicity studies incorporated environmental weathering of any kind, and only $6 \%$ explicitly studied photodegraded materials. Although data are scarce and our knowledge is based exclusively on pure polymers, the impacts of photochemical weathering appear to be mixed. A couple of studies reported that exposure of plastic to sunlight increased toxicity, ${ }^{68,69}$ one reported no major impact, ${ }^{70}$ and another reported decreased toxicity. ${ }^{71}$ Our collective findings indicate that a comprehensive and accurate understanding of the fate and impacts of marine plastic pollution-a critical step toward establishing evidence-based policies and developing next-generation materials-requires the research community to embrace the diverse formulations and sunlight-driven transformations of plastics in the environment.

\section{ASSOCIATED CONTENT}

\section{Supporting Information}

The Supporting Information is available free of charge at https://pubs.acs.org/doi/10.1021/acs.est.1c02272.

Methods and results for elemental analysis of the plastics; XRD measurements; the comparison of 
photo-reactivity in MilliQ water versus artificial seawater; methods and additional results for the carbon isotope measurements; and methods for FT-ICR-MS analysis; pictures of plastics used; irradiance spectra for each solar simulator configuration; additional characterizations of the plastics; additional FT-ICR-MS and carbon isotope data (PDF)

\section{AUTHOR INFORMATION}

\section{Corresponding Author}

Collin P. Ward - Department of Marine Chemistry and Geochemistry, Woods Hole Oceanographic Institution, Woods Hole, Massachusetts 02543, United States; 이이.org/ 0000-0003-2979-0280; Phone: 508-289-2931;

Email: cward@whoi.edu

\section{Authors}

Anna N. Walsh - Department of Marine Chemistry and Geochemistry, Woods Hole Oceanographic Institution, Woods Hole, Massachusetts 02543, United States; Department of Civil and Environmental Engineering, Massachusetts Institute of Technology, Cambridge, Massachusetts 02139, United States; (1) orcid.org/0000-0002-5694-7864

Christopher M. Reddy - Department of Marine Chemistry and Geochemistry, Woods Hole Oceanographic Institution, Woods Hole, Massachusetts 02543, United States; (1) orcid.org/0000-0002-7814-2071

Sydney F. Niles - National High Magnetic Field Laboratory, Florida State University, Tallahassee, Florida 32310-4005, United States; $\odot$ orcid.org/0000-0002-3487-6612

Amy M. McKenna - National High Magnetic Field Laboratory, Florida State University, Tallahassee, Florida 32310-4005, United States; Department of Chemistry, Colorado State University, Fort Collins, Colorado 80523, United States; 10 orcid.org/0000-0001-7213-521X

Colleen M. Hansel - Department of Marine Chemistry and Geochemistry, Woods Hole Oceanographic Institution, Woods Hole, Massachusetts 02543, United States; orcid.org/ 0000-0002-3506-7710

Complete contact information is available at: https://pubs.acs.org/10.1021/acs.est.1c02272

\section{Notes}

The authors declare no competing financial interest.

\section{ACKNOWLEDGMENTS}

We thank Alexandra Morrison (WHOI) and Dr. Anna Michel (WHOI) for assistance with initial plastic screenings and Dr. Krista Longnecker (WHOI) for DOC measurements. Funding was provided by the Seaver Institute, the Gerstner Family Foundation, Woods Hole Oceanographic Institution, and the National Science Foundation Graduate Research Fellowship Program (A.N.W.). The Ion Cyclotron Resonance user facility at the National High Magnetic Field Laboratory is supported by the National Science Foundation Division of Chemistry and Division of Materials Research through DMR-1644779 and the State of Florida. We thank John P. Quinn, Greg T. Blakney, Chad R. Weisbrod, and Christopher L. Hendrickson for design, maintenance and support for the $21 \mathrm{~T}$ FT-ICR mass spectrometer.

\section{REFERENCES}

(1) Kershaw, P. J.; Turra, A.; Galgani, F.; van Franeker, J. A. Guidelines for the Monitoring and Assessment of Plastic Litter in the Ocean; GESAMP, 2019.

(2) GESAMP Joint Group of Experts on the Scientific Aspects of Marine Environmental Protection. Sources, Fate and Effects of Microplastics in the Marine Environment: A Global Assessment. Reports Stud. GESAMP, 2015, 90, 96.

(3) Kershaw, P. J.; Rochman, C. M. Sources, Fate and Effect of Microplastics in the Marine Environment: Part 2 of a Global Assessment, 2015.

(4) Programme, U. N. E. Single-Use Plastics A Roadmap for Sustainability; United Nations Environment Programme, 2018.

(5) Kershaw, P. J.; Rochman, C. M. Sources, Fate and Effects of Microplastics in the Marine Environment; A Global Assessment, 2015.

(6) Law, K. L. Plastics in the Marine Environment. Annu. Rev. Mar. Sci. 2017, 9, 205-229.

(7) Ward, C. P.; Armstrong, C. J.; Walsh, A. N.; Jackson, J. H.; Reddy, C. M. Sunlight Converts Polystyrene to Carbon Dioxide and Dissolved Organic Carbon. Environ. Sci. Technol. Lett. 2019, 6, 669674.

(8) Song, Y. K.; Hong, S. H.; Eo, S.; Han, G. M.; Shim, W. J. Rapid Production of Micro- and Nanoplastics by Fragmentation of Expanded Polystyrene Exposed to Sunlight. Environ. Sci. Technol. 2020, 54, 11191.

(9) Zhu, L.; Zhao, S.; Bittar, T. B.; Stubbins, A.; Li, D. Photochemical Dissolution of Buoyant Microplastics to Dissolved Organic Carbon: Rates and Microbial Impacts. J. Hazard. Mater. 2020, 383, 121065.

(10) Gewert, B.; Plassmann, M.; Sandblom, O.; MacLeod, M. Identification of Chain Scission Products Released to Water by Plastic Exposed to Ultraviolet Light. Environ. Sci. Technol. Lett. 2018, 5, 272276.

(11) Gewert, B.; Plassmann, M. M.; MacLeod, M. Pathways for Degradation of Plastic Polymers Floating in the Marine Environment. Environ. Sci.: Processes Impacts 2015, 17, 1513-1521.

(12) Khaled, A.; Richard, C.; Redin, L.; Niinipuu, M.; Jansson, S.; Jaber, F.; Sleiman, M. Characterization and Photodegradation of Polybrominated Diphenyl Ethers in Car Seat Fabrics from End-of-Life Vehicles. Environ. Sci. Technol. 2018, 52, 1216-1224.

(13) Lee, Y. K.; Romera-Castillo, C.; Hong, S.; Hur, J. Characteristics of Microplastic Polymer-Derived Dissolved Organic Matter and Its Potential as a Disinfection Byproduct Precursor. Water Res. 2020, 175,115678 .

(14) Eyheraguibel, B.; Leremboure, M.; Traikia, M.; Sancelme, M.; Bonhomme, S.; Fromageot, D.; Lemaire, J.; Lacoste, J.; Delort, A. M. Environmental Scenarii for the Degradation of Oxo-Polymers. Chemosphere 2018, 198, 182-190.

(15) Eyheraguibel, B.; Traikia, M.; Fontanella, S.; Sancelme, M.; Bonhomme, S.; Fromageot, D.; Lemaire, J.; Lauranson, G.; Lacoste, J.; Delort, A. M. Characterization of Oxidized Oligomers from Polyethylene Films by Mass Spectrometry and NMR Spectroscopy before and after Biodegradation by a Rhodococcus Rhodochrous Strain. Chemosphere 2017, 184, 366-374.

(16) Shaw, J. B.; Lin, T.-Y.; Leach, F. E.; Tolmachev, A. V.; Tolic, N.; Robinson, E. W.; Koppenaal, D. W.; Paša-Tolić, L. 21 Tesla Fourier Transform Ion Cyclotron Resonance Mass Spectrometer Greatly Expands Mass Spectrometry Toolbox. J. Am. Soc. Mass Spectrom. 2016, 27, 1929-1936.

(17) Scheltema, R. A.; Hauschild, J.-P.; Lange, O.; Hornburg, D.; Denisov, E.; Damoc, E.; Kuehn, A.; Makarov, A.; Mann, M. The Q Exactive HF, a Benchtop Mass Spectrometer with a Pre-Filter, HighPerformance Quadrupole and an Ultra-High-Field Orbitrap Analyzer. Mol. Cell. Proteomics 2014, 13, 3698-3708.

(18) Schittmayer, M.; Birner-Gruenberger, R. Resolution Ladder for High-Resolution Mass Spectrometry. Anal. Chem. 2017, 89, 96119615.

(19) Smith, D. F.; Podgorski, D. C.; Rodgers, R. P.; Blakney, G. T.; Hendrickson, C. L. 21 Tesla FT-ICR Mass Spectrometer for 
Ultrahigh-Resolution Analysis of Complex Organic Mixtures. Anal. Chem. 2018, 90, 2041-2047.

(20) Hendrickson, C. L.; Quinn, J. P.; Kaiser, N. K.; Smith, D. F.; Blakney, G. T.; Chen, T.; Marshall, A. G.; Weisbrod, C. R.; Beu, S. C. 21 Tesla Fourier Transform Ion Cyclotron Resonance Mass Spectrometer: A National Resource for Ultrahigh Resolution Mass Analysis. J. Am. Soc. Mass Spectrom. 2015, 26, 1626-1632.

(21) Geyer, R.; Jambeck, J. R.; Law, K. L. Production, Use, and Fate of All Plastics Ever Made. Sci. Adv. 2017, 3, No. e1700782.

(22) Hahladakis, J. N.; Velis, C. A.; Weber, R.; Iacovidou, E.; Purnell, P. An Overview of Chemical Additives Present in Plastics: Migration, Release, Fate and Environmental Impact during Their Use, Disposal and Recycling. J. Hazard. Mater. 2018, 344, 179-199.

(23) Rochman, C. M. The Complex Mixture, Fate and Toxicity of Chemicals Associated with Plastic Debris in the Marine Environment. Marine Anthropogenic Litter; Springer International Publishing: Cham, 2015; pp 117-140.

(24) Khaled, A.; Rivaton, A.; Richard, C.; Jaber, F.; Sleiman, M. Phototransformation of Plastic Containing Brominated Flame Retardants: Enhanced Fragmentation and Release of Photoproducts to Water and Air. Environ. Sci. Technol. 2018, 52, 11123-11131.

(25) Romera-Castillo, C.; Pinto, M.; Langer, T. M.; Álvarez-Salgado, X. A.; Herndl, G. J. Dissolved Organic Carbon Leaching from Plastics Stimulates Microbial Activity in the Ocean. Nat. Commun. 2018, 9, $1-7$.

(26) Oliviero, M.; Tato, T.; Schiavo, S.; Fernández, V.; Manzo, S.; Beiras, R. Leachates of Micronized Plastic Toys Provoke Embryotoxic Effects upon Sea Urchin Paracentrotus Lividus. Environ. Pollut. 2019, 247, 706-715.

(27) Ocean Conservancy. International Coastal Cleanup 2017, 2017.

(28) Erni-Cassola, G.; Zadjelovic, V.; Gibson, M. I.; Christie-Oleza, J. A. Distribution of Plastic Polymer Types in the Marine Environment; A Meta-Analysis. J. Hazard. Mater. 2019, 369, 691698.

(29) Ward, C. P.; Sleighter, R. L.; Hatcher, P. G.; Cory, R. M. Insights into the Complete and Partial Photooxidation of Black Carbon in Surface Waters. Environ. Sci.: Processes Impacts 2014, 16, 721-731.

(30) ASTM International. ASTM D 2974 - Standard Test Methods for Moisture, Ash, and Organic Matter of Peat and Other Organic Soils; ASTM Int., 2014; i(April), pp 1-4. .

(31) Pereira, J. S. F.; Knorr, C. L.; Pereira, L. S. F.; Moraes, D. P.; Paniz, J. N. G.; Flores, E. M. M.; Knapp, G. Evaluation of Sample Preparation Methods for Polymer Digestion and Trace Elements Determination by ICPMS and ICPOES. J. Anal. At. Spectrom. 2011, 26, 1849-1857.

(32) Farfan, G. A.; Cordes, E. E.; Waller, R. G.; DeCarlo, T. M.; Hansel, C. M. Mineralogy of Deep-Sea Coral Aragonites as a Function of Aragonite Saturation State. Front. Mar. Sci. 2018, 5, 473.

(33) Ward, C. P.; Cory, R. M. Chemical Composition of Dissolved Organic Matter Draining Permafrost Soils. Geochim. Cosmochim. Acta 2015, 167, 63-79.

(34) Dittmar, T.; Koch, B.; Hertkorn, N.; Kattner, G. A Simple and Efficient Method for the Solid-Phase Extraction of Dissolved Organic Matter (SPE-DOM) from Seawater. Limnol. Oceanogr.: Methods 2008, 6, 230-235.

(35) Ward, C. P.; Cory, R. M. Complete and Partial PhotoOxidation of Dissolved Organic Matter Draining Permafrost Soils. Environ. Sci. Technol. 2016, 50, 3545-3553.

(36) Xu, L.; Roberts, M. L.; Elder, K. L.; Kurz, M. D.; McNichol, A. P.; Reddy, C. M.; Ward, C. P.; Hanke, U. M. Radiocarbon in Dissolved Organic Carbon by Uv Oxidation: Procedures and Blank Characterization at Nosams. Radiocarbon 2021, 63, 357-374.

(37) Blakney, G. T.; Hendrickson, C. L.; Marshall, A. G. Predator data station: A Fast Data Acquisition System for Advanced FT-ICR MS Experiments. Int. J. Mass Spectrom. 2011, 306, 246-252.

(38) Corilo, Y. E. PetroOrg Software; Florida State University, Omics LLC: Tallahassee, FL, 2014.
(39) Savory, J. J.; Kaiser, N. K.; McKenna, A. M.; Xian, F.; Blakney, G. T.; Rodgers, R. P.; Hendrickson, C. L.; Marshall, A. G. Parts-PerBillion Fourier Transform Ion Cyclotron Resonance Mass Measurement Accuracy with a "Walking" Calibration Equation. Anal. Chem. 2011, 83, 1732-1736.

(40) Xian, F.; Hendrickson, C. L.; Blakney, G. T.; Beu, S. C.; Marshall, A. G. Automated Broadband Phase Correction of Fourier Transform Ion Cyclotron Resonance Mass Spectra. Anal. Chem. 2010, 82, 8807-8812.

(41) Allen, N. S. A Study of the Light Absorption Properties of Polymer Films Using UV-Visible Derivative Spectroscopy. Polym. Photochem. 1981, 1, 43-55.

(42) Mills, A.; Le Hunte, S. An Overview of Semiconductor Photocatalysis. J. Photochem. Photobiol., A 1997, 108, 1-35.

(43) Cataldo, F. An Investigation on the Optical Properties of Carbon Black, Fullerite, and Other Carbonaceous Materials in Relation to the Spectrum of Interstellar Extinction of Light. Fullerenes, Nanotubes, Carbon Nanostruct. 2002, 10, 155-170.

(44) Lee, Y. K.; Murphy, K. R.; Hur, J. Fluorescence Signatures of Dissolved Organic Matter Leached from Microplastics: Polymers and Additives. Environ. Sci. Technol. 2020, 54, 11905-11914.

(45) Hakkarainen, M.; Albertsson, A.-C. Environmental Degradation of Polyethylene. Advances in Polymer Science; Springer: Berlin, Heidelberg, 2004; pp 177-200.

(46) Ranby, B.; Lucki, J. New Aspects of Photodegradation and Photooxidation of Polystyrene. Pure Appl. Chem. 1980, 52, 295-303.

(47) Geuskens, G.; David, C. The Photo-Oxidation of Polymers. A Comparison with Low Molecular Weight Compounds. Pure Appl. Chem. 1979, 51, 233-240.

(48) Miller, W. L.; Zepp, R. G. Photochemical Production of Dissolved Inorganic Carbon from Terrestrial Organic Matter: Significance to the Oceanic Organic Carbon Cycle. Geophys. Res. Lett. 1995, 22, 417-420.

(49) Austin, A. T.; Méndez, M. S.; Ballaré, C. L. Photodegradation Alleviates the Lignin Bottleneck for Carbon Turnover in Terrestrial Ecosystems. Proc. Natl. Acad. Sci. U.S.A. 2016, 113, 4392-4397.

(50) Spencer, R. G. M.; Stubbins, A.; Hernes, P. J.; Baker, A.; Mopper, K.; Aufdenkampe, A. K.; Dyda, R. Y.; Mwamba, V. L.; Mangangu, A. M.; Wabakanghanzi, J. N.; Six, J. Photochemical Degradation of Dissolved Organic Matter and Dissolved Lignin Phenols from the Congo River. J. Geophys. Res. 2009, 114, G03010.

(51) Bowen, J. C.; Ward, C. P.; Kling, G. W.; Cory, R. M. Arctic Amplification of Global Warming Strengthened by Sunlight Oxidation of Permafrost Carbon to CO2. Geophys. Res. Lett. 2020, 47, No. e2020GL087085.

(52) Wang, H.; Zhou, H.; Ma, J.; Nie, J.; Yan, S.; Song, W. Triplet Photochemistry of Dissolved Black Carbon and Its Effects on the Photochemical Formation of Reactive Oxygen Species. Environ. Sci. Technol. 2020, 54, 4903-4911.

(53) Fu, H.; Liu, H.; Mao, J.; Chu, W.; Li, Q.; Alvarez, P. J. J.; Qu, X.; Zhu, D. Photochemistry of Dissolved Black Carbon Released from Biochar: Reactive Oxygen Species Generation and Phototransformation. Environ. Sci. Technol. 2016, 50, 1218-1226.

(54) Niles, S. F.; Chacón-Patiño, M. L.; Putnam, S. P.; Rodgers, R. P.; Marshall, A. G. Characterization of an Asphalt Binder and Photoproducts by Fourier Transform Ion Cyclotron Resonance Mass Spectrometry Reveals Abundant Water-Soluble Hydrocarbons. Environ. Sci. Technol. 2020, 54, 8830-8836.

(55) Nelson, T. F.; Reddy, C. M.; Ward, C. P. Product Formulation Controls the Impact of Biofouling on Consumer Plastic Photochemical Fate in the Ocean. Environ. Sci. Technol. 2021, 55, 88988907.

(56) Goldstone, J. V.; Pullin, M. J.; Bertilsson, S.; Voelker, B. M. Reactions of Hydroxyl Radical with Humic Substances: Bleaching, Mineralization, and Production of Bioavailable Carbon Substrates. Environ. Sci. Technol. 2002, 36, 364-372.

(57) DuPont. DuPont Ti-Pure. Titanium Dioxide Polymers, Light and the Science of $\mathrm{TiO}_{2}, 2007$. 
(58) Tanniru, M.; Misra, R. D. K. On Enhanced Impact Strength of Calcium Carbonate-Reinforced High-Density Polyethylene Composites. Mater. Sci. Eng., A 2005, 405, 178-193.

(59) Leong, Y. W.; Abu Bakar, M. B.; Ishak, Z. A. M.; Ariffin, A.; Pukanszky, B. Comparison of the Mechanical Properties and Interfacial Interactions between Talc, Kaolin, and Calcium Carbonate Filled Polypropylene Composites. J. Appl. Polym. Sci. 2004, 91, 33153326.

(60) Day, R. E. The Role of Titanium Dioxide Pigments in the Degradation and Stabilisation of Polymers in the Plastics Industry. Polym. Degrad. Stab. 1990, 29, 73-92.

(61) Du, J.; Xu, S.; Zhou, Q.; Li, H.; Fu, L.; Tang, J.; Wang, Y.; Peng, $\mathrm{X}$; Xu, Y.; Du, X. A Review of Microplastics in the Aquatic Environmental: Distribution, Transport, Ecotoxicology, and Toxicological Mechanisms. Environ. Sci. Pollut. Res. 2020, 27, 11494-11505.

(62) Bucci, K.; Tulio, M.; Rochman, C. M. What Is Known and Unknown about the Effects of Plastic Pollution: A Meta-analysis and Systematic Review. Ecol. Appl. 2020, 30, No. e02044.

(63) Gunaalan, K.; Fabbri, E.; Capolupo, M. The Hidden Threat of Plastic Leachates: A Critical Review on Their Impacts on Aquatic Organisms. Water Res. 2020, 184, 116170.

(64) Rillig, M. C. Microplastic Disguising As Soil Carbon Storage. Environ. Sci. Technol. 2018, 52, 6079-6080.

(65) Seeley, M. E.; Song, B.; Passie, R.; Hale, R. C. Microplastics Affect Sedimentary Microbial Communities and Nitrogen Cycling. Nat. Commun. 2020, 11, 2372.

(66) Dees, J. P.; Ateia, M.; Sanchez, D. L. Microplastics and Their Degradation Products in Surface Waters: A Missing Piece of the Global Carbon Cycle Puzzle. ACS ES\&T Water 2021, 1, 214-216.

(67) Andrady, A. L. Microplastics in the Marine Environment. Mar. Pollut. Bull. 2011, 62, 1596-1605.

(68) Wang, X.; Zheng, H.; Zhao, J.; Luo, X.; Wang, Z.; Xing, B. Photodegradation Elevated the Toxicity of Polystyrene Microplastics to Grouper (Epinephelus Moara) through Disrupting Hepatic Lipid Homeostasis. Environ. Sci. Technol. 2020, 54, 6202-6212.

(69) Gewert, B.; MacLeod, M.; Breitholtz, M. Variability in Toxicity of Plastic Leachates as a Function of Weathering and Polymer Type: A Screening Study with the Copepod Nitocra Spinipes. Biol. Bull. 2021, 240, 191-199.

(70) Rummel, C. D.; Escher, B. I.; Sandblom, O.; Plassmann, M. M.; Arp, H. P. H.; MacLeod, M.; Jahnke, A. Effects of Leachates from UVWeathered Microplastic in Cell-Based Bioassays. Environ. Sci. Technol. 2019, 53, 9214.

(71) Zou, W.; Xia, M.; Jiang, K.; Cao, Z.; Zhang, X.; Hu, X. PhotoOxidative Degradation Mitigated the Developmental Toxicity of Polyamide Microplastics to Zebrafish Larvae by Modulating Macrophage-Triggered Proinflammatory Responses and Apoptosis. Environ. Sci. Technol. 2020, 54, 13888. 